\title{
The Transferability Level of Junior High School Students in Solving Geometry Problems
}

\author{
Anisa Agustin', Endah Retnowati ${ }^{1 *}$, Khar Thoe $\mathrm{Ng}^{2}$ \\ ${ }^{1}$ Universitas Negeri Yogyakarta, Indonesia \\ ${ }^{2}$ SEAMEO RECSAM, Malaysia \\ *Correspondence to: e.retno@uny.ac.id
}

Abstract: Transferability indicates that learners are able to use their knowledge to solve advanced problems. This study aimed to elaborate in detail the level of transferability both near and far transferability of junior high school students in solving geometry problems, and to reveal some factors causing errors in doing the knowledge transfer. Geometry in this study covered solid prism and pyramid. This qualitative descriptive study involved as many as 157 Grade VIII students in one of the junior high schools in Sleman Regency, Indonesia. The data were collected through a written test taken by all participants and interviews with 16 students selected based on the category of the transfer test results. This results of the study showed that (1) based on the average test scores, all students acquired fair transferability, (2) based on the near transfer test item, all students could be categorized as having high transferability, (3) based on the far transfer test items, all students could be categorized as having low transferability, (4) The factors that caused student errors were: (i) difficulties in showing information of what is known in the given context of the transfer problem; (ii) difficulties in stating what is asked in the given problems; (iii) difficulties in using conceptual, procedural, and technical knowledge in executing the strategy of solution; (iv) difficulties in drawing correct conclusions. This result of this study have raised concerns regarding the importance of learning strategy that facilitate transferability.

Keywords: transferability; near transfer; far transfer; factor of student errors; geometry problem

Recommended citation: Agustin, A., Retnowati, E., Ng, Khar Toe. (2022). The Transferability Level of Junior High School Students in Solving Geometry Problems. Journal of Innovation in Educational and Cultural Research, 3(1), 59-69.

\section{INTRODUCTION}

Sweller, et. al (2011) state that learning should be indicated by the performance of transfer. Rebello, et al. (2007) argue that sometimes the ultimate goal of education is the learning transfer to apply what has been studied into new various situations. In line with this, Britton, et al. (2007) explain that the final goal of education is the transfer of knowledge. Anderson \& Krathwohl (2001) also state that the main goal of education is to enhance retention and transferability. It means that it is important for students to acquire sufficient knowledge so that they can cope and solve new problems they face, especially in the field of mathematics. Therefore, the ability to apply the knowledge that students in new situations or new problems is significant to solve mathematical problems.

The quality of mathematics education in Indonesia is still relatively low. It is indicated by the results of PISA test taken by Indonesian students. PISA stands for Program for International Student Assessment, an international study to assess the extent to which 15-year-old students acquire knowledge and skills in reading, math, and science. Indonesia is one of the countries participating in the PISA program. In 2018, Indonesia obtained scores for reading, mathematics, and science, respectively, 371, 379, and 396 from the OECD average score of 487, 487, and 489 (Kemendikbud, 2019). These results indicate that Indonesia is still below the average, especially in the mathematics category.

One of the factors that causes the bottom rank of the PISA test is that the teachers have not acquired the skills to make test items that can encourage, stimulate, and analyze a problem using good reasoning (Purwasih, 2020). This means that many teachers make more multiple-choice and memorization-based questions. Surya (2012) argues that one of the causes of students' low mastery in mathematics is that teachers have not provided enough opportunities for students to build their own knowledge. The ability to apply what has been learned to solve new problems, answer new questions, or facilitate the learning of new subject matter is called transferability (Mayer, 2002). Based on the relationship between the contexts used, transfer is divided into near transfer and far transfer. Near Transfer is a transfer between similar contexts. Meanwhile, far transfer is a transfer between contexts that seem to be totally different and unfamiliar (Mayer, 2002; Perkins \& Solomon, 
1992:4). Transferability is very important in mathematics education, as said by Britton et al. (2007), if knowledge and learning cannot be applied beyond the original learning context, the usefulness of knowledge becomes very imperfect.

One of the tests that measure transferability has been carried out by Dixon \& Brown (2012). The transferability of students can be noticed from answering both near and far transfer questions. Near transfer test items are questions having the same structure as learning. Meanwhile, the far transfer problem has a different structure, is unusual, is more difficult and complex, and requires more than three theorems to solve so that it needs a different solution strategy when learning. The conclusion stated that further research was needed to determine student performance at each step to answer the questions given, especially in the first step chosen by students.

Previous research on transferability has been carried out by Sugiman, et al. (2019), which shows that the value of students' transferability that could be improved through Goal-Free-Problem-based learning. In this study, transferability is a skill to employ previous knowledge to solve different mathematical problems. 'Different' in this case means that it is not the same as other fields or topics that students have studied before, so that the question is different from those students have worked on. Transferability is divided into two: near transfer and far transfer. Students are regarded to acquire transferability if they can solve near transfer and far transfer questions. There are many studies based on a Cognitive Load Theory that has explored how transfer can be facilitated when the instruction is designed based on learner's thinking mechanism (Sweller, 2020; Retnowati, et al., 2018). Therefore, it is reasonable to take account how far students have acquired the transferability.

Near transfer test items include a type of surface isomorphism problem, which is modified from questions that students have dealt with into unfamiliar questions because the context, concepts, level of difficulty, and completion procedures are almost the same, but the complexity of the numerical and or editorial abilities of the problem is different from what students have learned. Meanwhile, far transfer questions include deep isomorphism problems, which are modified from familiar to unfamiliar questions, because there are changes on the procedures and the structure of the questions that have been studied, so that the concepts used are modifications between concepts that students learn. If students have worked on/studied the exact same test items as the questions in this study, the test items are not regarded as transfer problems but retention because students only repeat the same questions.

One of the state junior high schools in Sleman Regency, Yogyakarta, Indonesia was chosen as the research location because the students' transferability at that school had not been investigated. The school is one of the junior high schools with outstanding achievements. It is based on the results of the 2019/2020 National Examination, it ranked 6th in the Sleman Regency. However, the documentation results showed that there were teachers who often made more multiple-choice question than math essay. Even, the teachers still provided daily test questions on the geometry material which was exactly the same as the practices. Meanwhile, when the teacher gave math essay questions, many students had not used the stages of problem solving. Students did more math essay assignments by directly answering questions without writing down what was found out and what was being asked. This means students and teachers had not fully understood the process of solving mathematical problems, especially more specific things about the characteristics of the problemsolving process itself.

Student Work Sheet and mathematics videos in distance learning are not enough to facilitate students to understand geometry materials. Distance learning is carried out due to a non-natural disaster, namely Covid-19 pandemic. In addition, teachers often found student work with misconceptions, especially solid geometry. For example, when the teacher made a question about a trapezoidal prism, many students thought that base is always at the bottom. However, the teacher did not know for sure about the causes, whether the error was due to students' misconceptions or other reason. Due to time limit, the teacher did not allocate time to have a clear discussion regarding the students' mistakes. By investigating the transferability of junior high school students and revealing the factors causing student errors in solving geometry problems, teachers can put some effort to solve the issue, by planning appropriate actions to improve student transfer skills.

\section{METHODS}

\section{Research Approach}

Based on the research objectives, it was qualitative descriptive research. In this study, the transferability of junior high school students in solving geometry problems was analyzed. Transfer questions were made as instrument to identify the transferability of junior high school students in solving geometry problems. 


\section{Data Source}

The data source in this study was a class of year VIII students at State Senior High School in Sleman Regency, Yogyakarta because they had met the criteria: all students had studied some knowledge of solid geometries (Prisms and Pyramid). In addition, the technological facilities owned by every student in the school could support online research. Based on the results of the 2019/2020 National Examination, this school was categorized having students with high math abilities. However, observations through the Google Classroom in mathematics lesson showed that the characteristics of the students as the subjects of this study were diverse. It was indicated by the daily test results of prism and pyramid materials, which were still below the standard set by the school. In addition, there were active and passive students, and some students were disciplined in submitting assignments, but some were not.

\section{Data Collection Technique}

The data in this study were collected from the results of tests, interviews, and documentation. The transferability test was as an instrument to identify students' transferability in solving geometry problems. The test in this study used 8 transfer test, divided into 4 near transfer and 4 far transfer questions. The results of this test were in the form of students' writing (answers/responses) to reveal how the transferability of junior high school students was in solving geometry problems. The test items first went through discussion with the research team and teacher, which were then revised to meet the criteria of transfer, and tested on the research participant. The tests were distributed online to them. Then, their answers were analyzed based on the guidelines made to identify students' transferability in solving geometry problems. It should be noted that the results of student work were not to assess student learning outcomes, but to find out their transferability level. Furthermore, interviews were conducted with students who often made mistakes in each stage of solving geometry problems.

\section{Data Collection Instruments \\ a. Test}

The first instrument used in the study was in the form of transfer math essay questions with the materials of area and volume of prisms and pyramids. The transfer questions in this study met the transferability indicator because they were developed based on the initial abilities of students at the school. In this case, students had studied triangles, quadrilaterals, characteristic of quadrilaterals, Pythagoras, comparisons, and algebra, which refer to the national curriculum had been used by the school. The transfer questions in this study were not the same as those that had been studied by the students, because the researchers had conducted observations on the learning activities of teachers and students in the Google Classroom for mathematics subjects and validated the transfer questions with the mathematics teachers. The example of transfer test can be seen in Table 1.

Table 1. The Example of Transfer Test

\begin{tabular}{l} 
Kind of Problem \\
\hline A pyramid with a square base is as follows. \\
practice problem \\
height of the upright side $(\mathrm{TP})=39 \mathrm{~cm}$. If the base is \\
square, calculate the surface area of the pyramid!
\end{tabular}


Near transfer problem

Far transfer problem
A pyramid with a square base is as follows.

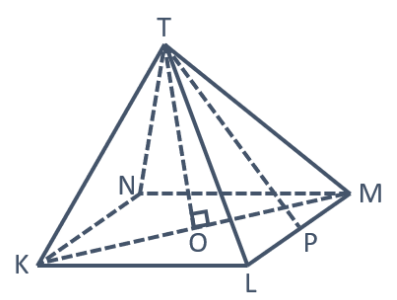

The height of the pyramid (TO) $=6 \mathrm{~cm}$ and the height of the upright side $(T P)=10 \mathrm{~cm}$. If the base is square, calculate the surface area of the pyramid!

A rhombic upright prism has the diagonal of the rhombus measuring $16 \mathrm{~cm}$ and $(2 p+6) \mathrm{cm}$. The perimeter of the base $(4 p+20) \mathrm{cm}$. While the prism height $(2 p) \mathrm{cm}$. The surface area of the prism is...

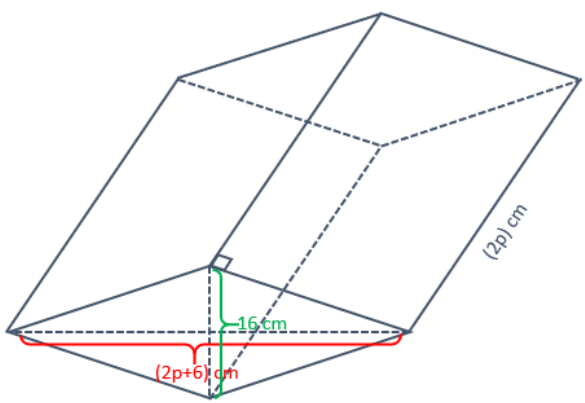

The test was carried out in 90 minutes including the submission of the answer sheets. The procedure of testing the transferability test instrument is as follows.

1. The researchers uploaded the transfer test items online.

2. Students downloaded transfer questions online.

3. Students copied and completed the statement of honesty and integrity.

4. Students worked on the transfer questions using sheets of paper.

5. Students submitted their answer sheets online.

The expected data in this study were the students' work steps in solving the geometry problems. Furthermore, an assessment was implemented based on the scoring rubric. The rubric was developed based on the four stage of general problem solving strategy. Each stage was scored 1 for correctness, and 0 for incorrectness. Then, means and SDs were calculated, and three categories were made to show the transferability level in solving geometry problems in general (Azwar, 2012) using the $M \pm S D$ terms, where $M$ is the Ideal mean that is $1 / 2 *$ (Max Score + Min Score), and SD is Standard Deviation that is $1 / 6 *$ (Max Score - Min Score). The procedure to assess student work is as follows.

1. Reading each student's answer and compare it with the answer key.

2. Scoring based on the rubric (Table 2).

3. Summing up the scores achieved by each student.

4. Categorizing the students' scores into categories of transferability.

Table 2. The Rubric of Transfer Test

\begin{tabular}{|c|c|c|}
\hline \multirow{2}{*}{$\begin{array}{r}\text { Problem } \\
\text { Solving Stages }\end{array}$} & \multicolumn{2}{|l|}{ Scoring } \\
\hline & 1 & 0 \\
\hline Known & $\begin{array}{l}\text { Shows all } \\
\text { information } \\
\text { correctly }\end{array}$ & $\begin{array}{l}\text { Not showing all the information } \\
\text { correctly or not writing anything } \\
\text { down }\end{array}$ \\
\hline Asked & $\begin{array}{l}\text { State the } \\
\text { concept/variable } \\
\text { asked correctly }\end{array}$ & $\begin{array}{l}\text { Did not state the concept/variable } \\
\text { that was asked correctly or did not } \\
\text { write anything down }\end{array}$ \\
\hline
\end{tabular}




\begin{tabular}{cll}
\hline \multirow{3}{*}{ Answer } & $\begin{array}{l}\text { Answer with the } \\
\text { steps of work } \\
\text { correctly }\end{array}$ & $\begin{array}{l}\text { Did not answer with the steps of } \\
\text { the work correctly or did not write } \\
\text { anything }\end{array}$ \\
Chow the & $\begin{array}{l}\text { Solution solution } \\
\text { as a conclusion } \\
\text { correctly }\end{array}$ & $\begin{array}{l}\text { Doesn't show the solution as a } \\
\text { conclusion correctly or doesn't write } \\
\text { anything down }\end{array}$ \\
\hline
\end{tabular}

\section{b. Interviews}

This study employed a semi-structured interview. Interviews were used to reveal the factors causing students' mistakes in doing the transferability test. From the results of the transferability test with the answer sheet of what is known, asked, answered, and concluded, the selected students who often made mistakes in filling out each stage were interviewed regarding the causes of their errors in solving geometry problems. The development of interview guidelines was based on a general problem-solving strategy. The interviews were conducted online using WhatsApp application. How to conduct interview in this study is as follows.

1. Contacting students via phone call to ask for their willingness to conduct interviews.

2. Making a phone call.

3. Saying greetings, introductions, and ensuring that the interview was done in the students' convenient time

4. Creating a relaxed and fun atmosphere by asking questions outside the interview guidelines

5. Conducting and recording interviews based on the guidelines

6. Thanking and closing.

\section{Data Analysis Technique}

The data analysis was carried out during and after data collection. It was intended to achieve the research objectives. The stages of analysis are as follows: giving a score based on the rubric validated among researchers, making a recap by sorting the highest to the lowest score, interviewing students who often made mistakes, where the interview components were related to the causes of student errors at each stage of problem solving. Then, the researchers conducted data reduction, data display, and conclusion drawing (Miles \& Huberman, 1994).

\section{RESULT AND DISCUSSION}

The data of transferability were collected from the answers of 157 Grade VIII students who worked on the transfer questions. Transfer questions were used to determine the transferability in solving geometry problems. From the identification of the answers to the transfer questions, 45 students were in the high transferability category, 63 students acquired fair transferability, and 49 students were categorized in the low transferability.

\section{Based on the General Transferability}

Overall, the students obtained an average of 15.656 or $49 \%$ which was classified as acquiring fair transferability. This was because students worked more on near transfer questions correctly than far transfer questions. This means that in general, the junior high school students were quite capable of working on questions whose context, concepts, and solutions were almost the same as those studied, in which the problem or quantity was different. However, on complex questions, which required more concepts to be linked and had the different structure of the questions, students were not optimal in solving the problem.

\section{Based on the Near Transfer Problems}

In the near transfer question, 22 students out of 157 completed 4 near transfer questions correctly with the strategies provided. However, in each near transfer question, Number 1 was solved correctly by 108 students; Number 2 was answered correctly by 50 students; Number 3 was solved correctly by 63 students, and Number 4 was solved correctly by 69 students. Therefore, the most difficult near transfer problem was Number 2, the problem of the area of a square pyramid involving Pythagoras. Based on the results, most students did not use the Pythagorean concept to solve problems and more often directly employed the provided information to help answer the questions. This caused students to make errors. In general, the average obtained by students on near transfer questions was 11.153 or $70 \%$, which was classified as high category.

\section{Based on the Far Transfer Problems}

In the far transfer problem, no student had completed 4 correct questions with the strategies provided. However, in each of the far transfer questions, Number 1 was solved correctly by 7 students; Number 2 was 
solved correctly by 15 students; Number 3 was solved correctly by 26 students; and Number 4 was solved correctly by 17 students. Hence, the most difficult far transfer test item was Number 1, the problem of the surface area of a rhombic prism involving Pythagoras and algebraic forms. In observing the test results, most students did not answer the question. Even if someone tried to solve it, he/she did not employ the two concepts. Most could not see the connection between Pythagoras and algebraic forms as part of solving problems. In general, the average obtained by students on the far transfer questions was 4.503 or $28 \%$, which was classified as a low category.

\section{Based on the Problem-Solving Stages}

The transferability of students, which was still not optimal in this study, was referred to by an assessment for problem solving stages. A general problem solving strategy involves analyzing problems, planning problem solving, carrying out actions, and drawing conclusions. Based on these 4 stages, the steps were made based on the guidelines, namely what is known, what is asked, answer, and conclusion. The discussion in this study is elaborated as follows.

\section{Near Transfer Test Items \\ What is known}

In this section, one student did not write what he knew correctly so that he obtained the lowest score for this stage. However, to find out the factors that caused errors in this section, there were three students who could provide information on the frequent errors about near transfer.

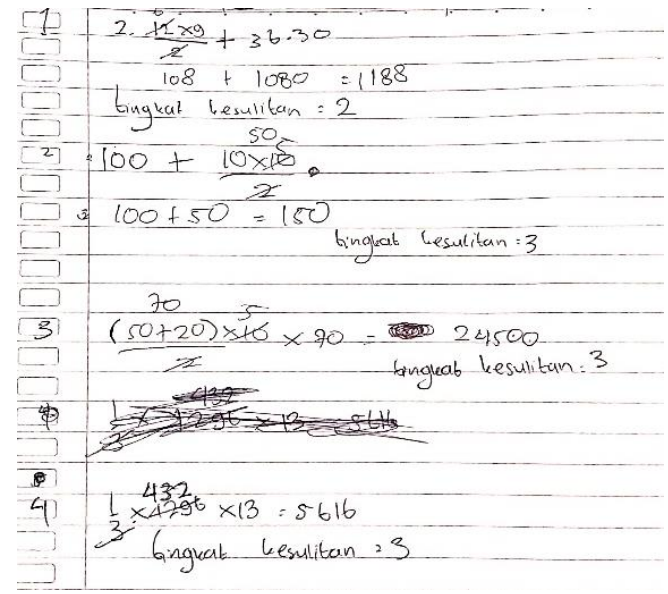

Figure 1. Example of an incorrect student answer to near transfer questions

This is an example of student's answers with frequent mistakes in the sections of what is known and what is asked about near transfers. On the results of the transfer test, the student was categorized as having low transferability. The following is an interview with student Code C8.

P : "What do you know from Question Number 1 (near transfer)?"

C8 : "Is that a prism?"

P : "What do you think of it?"

C8 : "What I know is the length is 12, 9, and 15, and the height of prism"

P : "During the test, why did you work directly on the answer, without providing what you know, what was asked, and conclusion?"

C8 : "I did it straight away without writing those aspects"

$\mathrm{P}$ : "Why didn't you give us what is known, what is asked, and conclusions?"

C8 : "I only took a look at the question, Ma'am"

Students thought that they had understood the near transfer problem, even though they did not write what was known. When asked to show it, the student tended to be unsure of what was being conveyed. Students were more often confused and forgot to reexplain the answer. Even on questions that were answered correctly, students still doubted what they knew. In addition, other students were not motivated and unwilling in writing, so they felt they did not need to write down what they knew and directly answered the near transfer questions. Students were also more likely to answer in a hurry and to finish quickly than to understand the problems provided.

\section{What is asked}

In this section, one student did not write down what was asked correctly so that he obtained the lowest 
score. However, to find out the factors that caused student errors in this section, three students could provide information on the frequent errors in the section about near transfers. The following is an interview with Student Code C5.

$P$ : "Why didn't you write down what was known and asked (Number 3 Near Transfer)?"

C5 : "In math essay, I often didn't write down what was known and asked, Ma'am, so I answered right away".

P : "How does the teacher teach to solve the math essay problem?"

C5 : "What is known and asked are written, Ms., sometimes, but I never write it"

P : "Why didn't you write it down?"

C5 : "To finish it quickly, it took a long time to write them down."

P : "If so, what do you know from Question Number 3?"

C5 : "The height of the vessel is $10 \mathrm{dm}$; the length is $70 \mathrm{dm}$; the bottom is $20 \mathrm{dm}$; the top is $50 \mathrm{dm}$ "

$\mathrm{P} \quad$ : "What is the shape of the vessel??"

C5 : "Is it a trapezoid?"

$\mathrm{P} \quad$ : "Is there any geometry called a trapezoid??"

C5 : "Not sure"

$\mathrm{P} \quad$ : "What is the question?"

C5 : "The question is the volume of water that can fill the vessel"

$\mathrm{P} \quad$ : "What does that question mean?"

C5 : "No clue"

$\mathrm{P} \quad$ : "Can 'what is known' directly answer 'what is asked'?"

C5 : "No clue"

Students admitted that they did not write down what was asked to answer the questions quickly. By reading the four near transfer questions provided, students could only mention what was being asked, because when asked whether what is known can directly answer what is asked, students tended to hesitate, got confused, and forgot. This means that students actually had not been able to state what was asked as part of solving geometry problems because they were not sure of the plan, they would use to answer the near transfer problem.

\section{Solution of the problem}

In this section, 12 students could not correctly show how to answer the near transfer question so that they obtained the lowest score in the section. There were also 3 students who could provide information on the frequent errors in the answer section on near transfer questions.

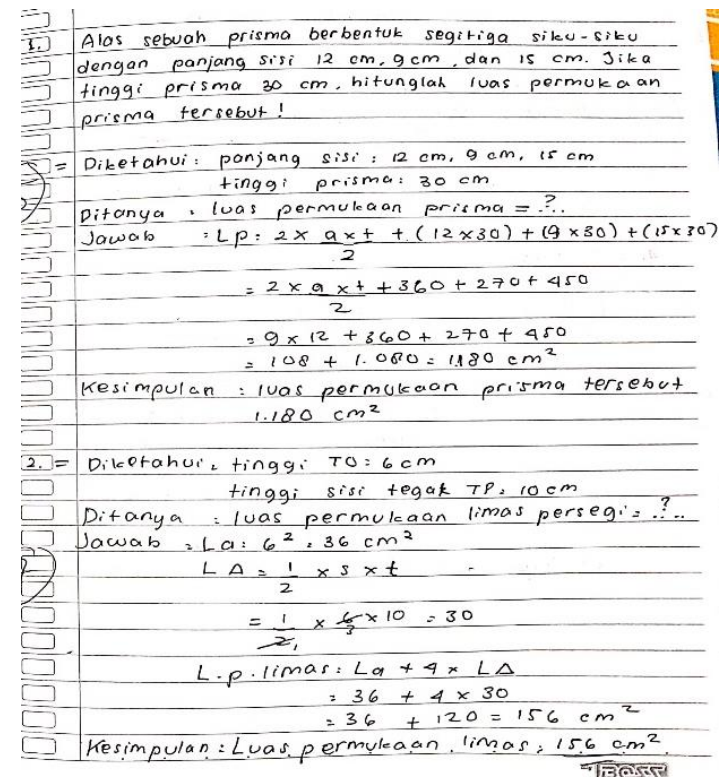

Figure 2a. Example of student's incorrect answer to near transfer questions

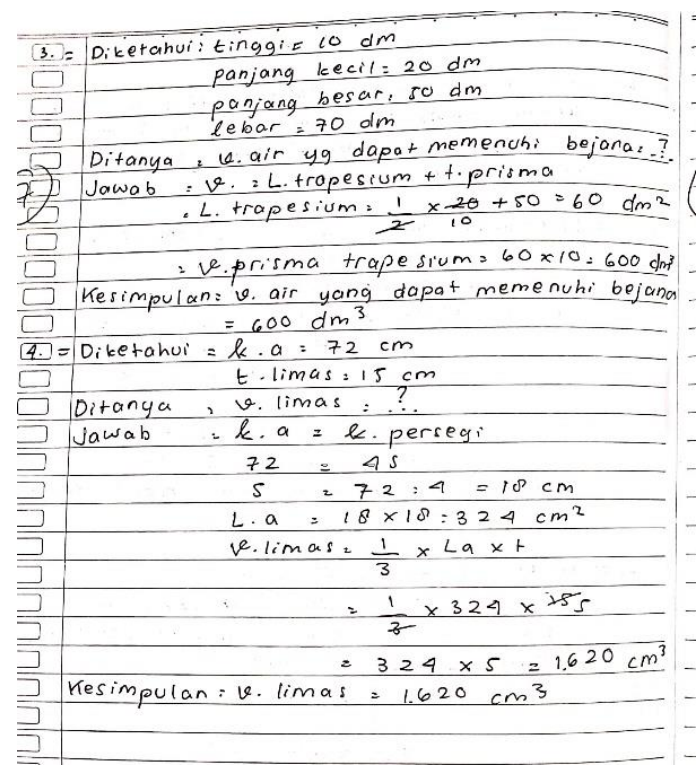

Figure 2b. Continued - Example of student's incorrect answer to near transfer questions

\section{Conclusion}

For this section, 28 students could not draw a correct conclusion at all, so they obtained the lowest score. In this section, there were also three students who could provide information on the frequent errors in the conclusion section of the near transfer question. The following is an interview with Student Code A29. 
P : "How did you conclude your answer (Number 1 Near Transfer)?"

A29 : "Actually, I was only concluding what was known and the answer"

P : :How were you sure your answer was correct?"

A29 : "Just instinct"

P : "How did you conclude your answer (Number 2 near transfer)?"

A29 : "Actually, it was just the same, I only rewrote the answer in the conclusion part."

Students only rewrote the results obtained when answering without re-checking the answers. The reasons were that they felt sure that the answer was correct. Besides, students got confused about what to write at the conclusion, which was time consuming, and finally decided not to re-check the answer.

\section{Far transfer Questions \\ What is known}

In this section, 53 students did not write what they knew correctly, so they got the lowest score. Based on the observation on the transferability test results, most students chose not to answer all the far transfer questions at all, which impacted in the lowest score in this section. For this section, 3 students provided information on the frequent errors in the far transfer problem. The following is an interview with Student Code E8.

P : : "Why didn't you answer the far transfer question?"

E8 : "I ran out of time"

P : :Why?"

E8 : "I did not concentrate well and took a long time for my attempt"

P : "What do you mean?"

E8 : "I took a long time about near transfers and was not in the mood to work on the test"

P : : "What do you know from question Number 1 (far transfer)?"

E8 : "The length of the diagonal is what I know, but I still got confused about the circumference of the base and the height of the prism"

P : :What did you get from what you knew?"

E8 : "I didn't get it, especially the one with the brackets"

Students felt they did not have enough time to understand the far transfer problem and lacked motivation to answer the questions. Besides, students did not understand it because they did not read the questions thoroughly. When asked to show what they know, students tended to only mention the words or pictures without mentioning the specified size and did not process the known information.

\section{What is asked}

In this section, 49 students did not write down what was asked correctly at all so that they achieved the lowest score for the question section. Based on the transferability test results, most students chose not to answer all the far transfer questions at all which impacted in the low score in this section. Also, in this section there were 3 students who could provide information on the frequent errors. The following is an interview with Student Code E17.

P : "What is asked? (Number 2 far transfer)?"

E17 : "Area of upright side"

P : "How did you understand what was being asked? Which one is side of the pyramid?"

E17 : "The upright side is the one that is slightly upwards, the slightly sloping side, or if not the height of pyramid"

$\mathrm{P} \quad$ : "What is the difference between the perpendicular side of the pyramid and the height of the perpendicular side??"

E17 : "No clue"

Students did not completely understand what was being asked. When students were asked about it, students knew what was asked but they could not explain the next plan.

\section{Solution}

In this section, 99 students could not correctly show how to answer the far transfer question so that they obtained the lowest score for this part. In this section, 3 students could provide information on the frequent errors in the answer section for far transfer questions. The following is an interview with Student Code A26.

$P \quad$ : "Try to re-explain how you got the result (Number 1 Far Transfer)?"

A26 : "I only tried to answer it, $2 \times L a+K a \times t$, La $=16 \times(2 p+6) / 2$, because it is a rhombus, the circumference of the base $(4 p+20) \times 2 p$, and $2 \times 16 \times 2 p+6 / 2+4 p+20 \times 2 p=16 \times 2 p+6+8 p+20=$ $16 \times 10 p+26=616+10 p=6160$, I didn't know, so I just added 0 at the end"

$P \quad$ : "You had obtained information on what you know and what is asked, then how did you answer what was asked (Number 2 far transfer)" 
A26 : "Only looking for the base side: $18 \times 18=324$, so the base side is $18 \mathrm{~cm}$; I got confused about the height"

P : "If you're confused, I'm even more confused, just try to re-explain as best as you can, how did you answer what was asked?"

A26 : "Only $V=1 / 3 \times 324 \times t, 1296=108 x t, t=12$, and found the triangle, $18 \times 15 / 2,15$ was only my prediction, $6 \times 15=90$, I was mistaken, it should be 9 not 6 . It should be 135; maybe it should be multiplied by $4^{\prime \prime}$

In addition to blanking the answers, students still made mistakes in answering the far transfer questions because they had not implemented the plan properly. It was indicated by students who had not been able to connect concepts that should be combined with geometry such as Pythagoras, algebra, and comparison. Also, students only made mistakes in answering far transfer questions. In addition, students still made conceptual errors because they could not distinguish between volume and surface area of prisms and pyramids and due to miscalculations.

\section{Conclusion}

As many as 104 students could not draw a correct conclusion so they obtained the lowest score for the section. In this section, there were 3 students who could provide information on the frequent student errors of the far transfer question.

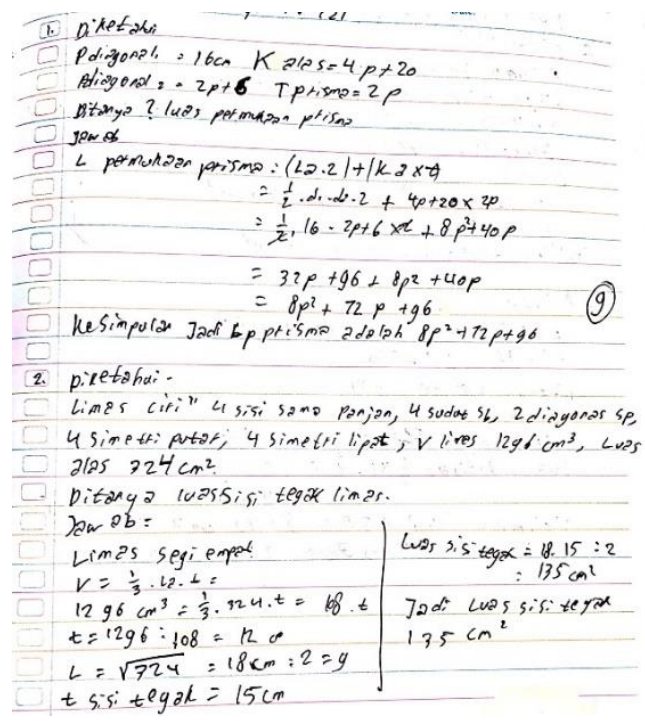

Figure 3a. The example of a student's answer with a wrong conclusion on the far transfer question

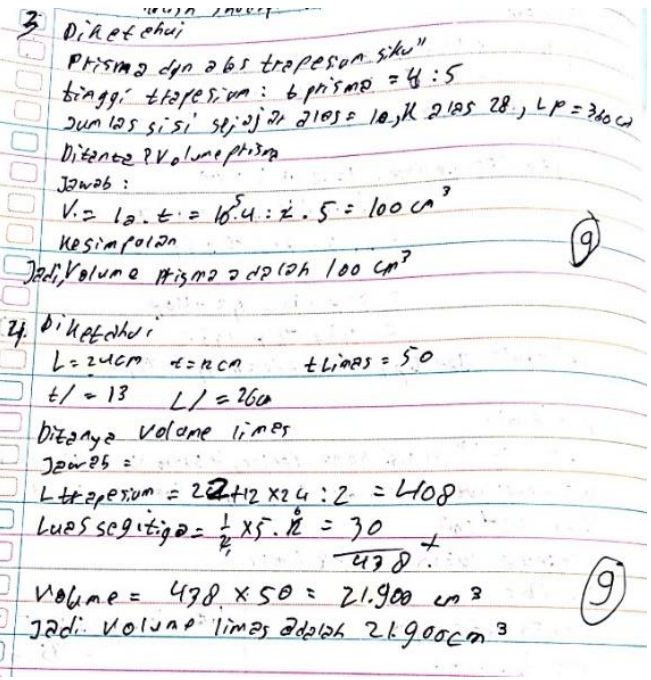

Figure 3b. Continued example of a student's answer with a wrong conclusion on the far transfer question

This is a student answer with frequent mistakes in the conclusion section of the far transfer question. On the results of the transfer test, the student was categorized as having high transferability. The following is an interview with Student Code A26.

P : : "How did you make a conclusion (Number 1 far transfer)?"

F21 : "That's the result of all the answers"

P : "How were you sure your answer was correct?"

F21 : "Because I did as best as I could, I felt like I was right; I had used the formula."

Also, students did not draw conclusions on the grounds of running out of time and they did it directly from the answers obtained in the process of answering transfer questions; they felt optimistic because they thought they had used the correct formula and method, so they did not re-check their answers.

Based on the data analysis results, from the students' answers to the transfer problem, 45 students acquired high transferability, 63 students were in the fair transferability category, and 49 students were categorized to have low transferability. Overall, students obtained an average score of 15.656 or $49 \%$, which was classified as having fair transferability. The near transferability of the State Junior High School 3 Godean students achieved an average of 11,153 or $70 \%$, which was considered high. However, the far transferability obtained an average of 4.503 or $28 \%$ which was relatively low.

Based on the interviews, the factors causing student errors in solving the geometry problems of the transferability test were as follows. First, students had not surely shown what information was known. Students thought they had understood the near transfer problem without writing down what was known. In addition, on the far transfer question, students incorrectly looked at the pictures provided and did not read the questions 
completely. Even, the students who could read as a whole did not necessarily understand the mastery of these words.

Secondly, students had not been able to mention what was asked as part of solving geometry problems because they were not sure of the plan that they would use to answer the near transfer questions. Meanwhile, in the far transfer problems, students tended not to understand the goals, so they only knew what was asked by reading the questions but had not been able to proceed to the next step to plan problem solving.

Thirdly, students had not been able to answer transfer questions successfully because in near transfer questions, students still made conceptual, procedural, and technical/calculation errors in the process of solving geometry problems. Meanwhile, in far transfer, in addition to mistakes in answering, students often made conceptual, procedural, and technical/calculation errors in the process of solving geometry problems. These might be referred to the basic knowledge to solve the problem which is specific in the domain. In other words, that students had not executed the completion plan on the transfer problem properly, due to their incompleted understanding of the specific problem solving strategy.

Lastly, students had not drawn the right conclusion on transfer questions because in near transfer questions students only rewrote the results without re-checking their answers. This was because students were sure that the answer was correct. In addition, in far transfer students thought that they ran out of time; they also drew conclusions directly based on the answers in the process of answering questions. Students felt optimistic because they thought they had used the appropriate formula and method, so they did not re-check the answer.

This study recommends the teachers to be able to create instructions that facilitate students to practice their transferability. Musa, et al. (2018) found similar results for arithmetic domain, and that not many students could perform transfer tests based on the general problem solving strategy. There are many instructions have been investigated by cognitive load theory in which assist students to construct and automate knowledge in efficient way (Xu, et al., 2021), as known that knowledge automation can help learners to transfer their learning (Paas \& van Merriënboer, 2020). Without disregarding the instructions that had been used by the teachers, learners are also the factors influencing the transferability. Hence, improving transfer requires contribution of all aspects during learning, not alone the teacher and the instructions.

\section{CONCLUSION}

It may be concluded that learning to be able to transfer knowledge might not be easy for some students. The core difficulty might be drawn from the failure of acquiring problem solving strategy, both in general and specific terms. This results of the study showed that (1) based on the average test scores, all students acquired fair transferability, (2) based on the near transfer test item, all students could be categorized as having high transferability, (3) based on the far transfer test items, all students could be categorized as having low transferability, (4) The factors that caused student errors were: (i) difficulties in showing information of what is known in the given context of the transfer problem; (ii) difficulties in stating what is asked in the given problems; (iii) difficulties in using conceptual, procedural, and technical knowledge in executing the strategy of solution; (iv) difficulties in drawing correct conclusions. The causes of number (iii) might be categorized as the incompleted ability of specific problem solving strategy. This result of this study should motivate us to yield in many more practical learning strategies that facilitate transferability.

\section{REFERENCES}

Anderson, W. L. \& Krathwohl, D. L. (2001). A taxonomy for learning teaching and assessing: a revision of bloom's taxonomy of educational objectives. New York, NY: Logman.

Azwar, S. (2012). Penyusunan skala psikologi. Yogyakarta: Pustaka Pelajar.

Britton, S., New, P., Roberts, A., et al. (2007). Investitating students' ability to transfer mathematics. Sydney: Sydney University Press.

Dixon, R. A. \& Brown, R. A. (2012). Transfer of learning: Connecting concepts during problem solving. Journal of Technology Education, 24(1), 2-17.

Kemendikbud. (2019). Hasil PISA Indonesia 2018. Siaran Press. Nomor: 397/Sipres/A5.3/XII/2019. https://www.kemdikbud.go.id/main/blog/2019/12/hasil-pisa-indonesia-2018-akses-makin-meluassaatnya-tingkatkan-kualitas

Mayer, R. E. (2002). Rote versus meaningful learning. Theory into Practice, 41(4), 226-232.

Miles, M. \& Huberman, M. (1994). Qualitative data analysis (2nd ed.). California, CA: Sage.

Musa, M., Suprapti, E., \& Soemantri, S. (2018). Analisis strategi peserta didik dalam menyelesaikan masalah sistem persamaan linear dua variabel. Jurnal Inovasi Pendidikan dan Pembelajaran Matematika, 4(2), 132-146. http://e-jurnal.unisda.ac.id/index.php/Inspiramatika/article/view/1270 
Paas, F., \& van Merriënboer, J. J. G. (2020). Cognitive-Load Theory: Methods to Manage Working Memory Load in the Learning of Complex Tasks. Current Directions in Psychological Science, 29(4), 394-398.

Purwasih, J. H. G. (2020). Kendala calon pendidik dalam membuat soal pilihan ganda higher order thinking (HOT). Jurnal Sosial Humaniora, 13(1), 12-22.

Perkins, D. N. \& Salomon, G. (1992). Transfer of learning. International Encyclopedia of Education, Second Edition. Oxford, England: Pergamon Press

Rebello, N. S., Cui, L., Bennett, A. G., et al. (2007). Transfer of learning in problem solving in the context of mathematics and physics. In Book: Learning to Solve Complex Scientific Problems, 223-246.

Retnowati, E., Ayres, P., \& Sweller, J. (2018). Collaborative learning effects when students have complete or incomplete knowledge. Applied Cognitive Psychology, 32(6), 681-692.

Sugiman, S., Retnowati, E., Ayres, P., et al. (2019). Learning goal-free problems: Collaboratively or individually? Jurnal Cakrawala Pendidikan, 38(3), 590-600.

Surya, E. (2012). Upaya pembelajaran matematika berbasis masalah dengan strategi konflik kognitif. Jurnal Tematik, 1(8), 1-14. http://digilib.unimed.ac.id/id/eprint/799

Sweller, J, Ayres, P, \& Kalyuga, S. (2011). Cognitive Load Theory. London: Springer

Sweller, J. (2020). Cognitive load theory and educational technology. Education Tech Research Dev 68, 116.

$\mathrm{Xu}, \mathrm{K}$. M., et al. (2021). A growth mindset lowers perceived cognitive load and improves learning: Integrating motivation to cognitive load. Journal of Educational Psychology, 113(6), 1177-1191. 